\title{
Resveratrol Inhibits the Epidermal Growth Factor-Induced Migration of Osteoblasts: the Suppression of SAPK/JNK and Akt
}

\author{
Tetsu Kawabata ${ }^{a, b}$ Haruhiko Tokudab,c Kazuhiko Fujita ${ }^{a, b}$ Shingo Kainuma,b \\ Go Sakaia ${ }^{a}$ Rie Matsushima-Nishiwaki ${ }^{b}$ Osamu Kozawa ${ }^{b}$ Takanobu Otsuka ${ }^{a}$ \\ aDepartment of Orthopedic Surgery, Nagoya City University Graduate School of Medical Sciences, \\ Nagoya, Aichi, Japan, 'Department of Pharmacology, Gifu University Graduate School of Medicine, Gifu, \\ Japan, 'Department of Clinical Laboratory, National Center for Geriatrics and Gerontology, Obu, Aichi, \\ Japan
}

\author{
Key Words \\ Resveratrol $\cdot \mathrm{EGF} \cdot$ Migration $\cdot$ Osteoblast $\cdot \mathrm{SAPK} / \mathrm{JNK} \cdot \mathrm{Akt}$
}

\begin{abstract}
Background/Aims: Resveratrol is a polyphenol enriched in the skins of grapes and berries, that shows various beneficial effects for human health. In the present study, we investigated the mechanism behind the epidermal growth factor (EGF)-induced migration of osteoblastlike MC3T3-E1 cells, and the effect of resveratrol on this cell migration. Methods: The cell migration was examined using Boyden chamber, and phosphorylation of each kinase was analyzed by Western blotting. Results: The EGF-induced migration was suppressed by PD98059, an inhibitor of MEK1/2, as well as SB203580, an inhibitor of p38 MAP kinase, SP600125, an inhibitor of SAPK/JNK, and deguelin, an inhibitor of Akt. In contrast, rapamycin, an inhibitor of upstream kinase of p70 S6 kinase, and fasudil, an inhibitor of Rho-kinase, hardly affected the migration. Resveratrol significantly reduced the EGF-induced migration in a dose-dependent manner. SRT1720, an SIRT1 activator, suppressed the migration by EGF. In addition, resveratrol markedly attenuated the EGF-induced phosphorylation of SAPK/JNK and Akt without affecting the phosphorylation of p44/p42 MAP kinase or p38 MAP kinase. The phosphorylation of SAPK/JNK and Akt induced by EGF was down-regulated by SRT1720. Conclusion: Our results strongly suggest that resveratrol reduces the EGF-stimulated migration of osteoblasts via suppression of SAPK and Akt, and that the inhibitory effect of resveratrol is mediated in part via SIRT1.
\end{abstract}

\section{Introduction}

It is firmly established that bone metabolism is strictly regulated by two types of functional cells $[1,2]$, with osteoblasts responsible for bone formation and osteoclasts for 


\section{Cellular Physiology Cell Physiol Biochem 2017;43:1025-1036

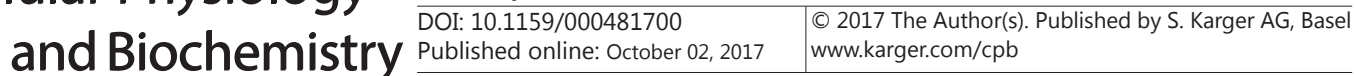 \\ Kawabata et al.: Resveratrol-Effect on Osteoblast Migration}

bone resorption. Bone tissue is continuously regenerated through a process known as a bone remodeling. The bone remodeling process begins with osteoclastic bone resorption followed by osteoblastic bone formation, and bone mass is appropriately maintained by the sophisticated coupling performance of osteoblasts and osteoclasts. The impairment of bone remodeling leads to metabolic bone diseases such as osteoporosis. The migration of osteoblasts is recognized as important for many processes essential to physiological bone metabolism, including bone remodeling and responses to mechanical loading $[1,3,4]$. However, accumulating evidence suggests that osteoblast migration is also crucial for bone pathological processes, such as the impairment of bone fracture repair and tumor metastasis [5]. Numerous humoral factors, such as epidermal growth factor (EGF), play essential roles in bone metabolism [3, 4,6]. Regarding the effects of EGF on osteoblasts, EGF reportedly stimulates the proliferation $[7,8]$ but inhibits the differentiation $[9,10]$. As for osteoblast migration, it has been shown that EGF promotes the migration of osteoblasts [11]. However, the details of the mechanism underlying EGF-induced migration of osteoblasts remain to be clarified.

Polyphenols are found in foods such as fruits and possess beneficial properties for human health through anti-oxidative, anti-inflammatory and anti-tumor effects $[12,13]$. Among polyphenolic compounds, resveratrol which is enriched in red grapes and berries delays the aging process, extends the lifespan and reduces the risk of numerous degenerative diseases $[14,15]$. The French population reportedly tends to smoke and take in saturated fatty acids in meals, however, the rate of cardiovascular events in this population is relatively low, probably due to the high consumption of wine containing abundant resveratrol [16]. A study on the relationship between wine and bone health recently showed that women, who preferentially consume wine, have a lower risk of hip fracture than non-drinkers, past drinkers and those with other alcohol preferences [17]. With regard to the molecular mechanism of resveratrol, it has been demonstrated that several effects of resveratrol are exerted through SIRT1, improving the cellular function and organismal health by binding to nicotinamide adenine dinucleotide (NAD+)-dependent deacetylase and enhancing its activity [18]. NAD+ is biosynthesized in human as a precursor in nicotinamide and has a crucial role as a coenzyme of oxidoreductase in energy acquisition. However, the exact mechanism underlying how resveratrol affects bone metabolism has not yet been elucidated.

In the present study, we investigated the mechanism behind the EGF-induced migration of osteoblast-like MC3T3-E1 cells, and the effect of resveratrol on the migration. We herein demonstrate that resveratrol inhibits EGF-induced migration of MC3T3-E1 cells through the down-regulation of SAPK/JNK and Akt and that the suppression by resveratrol is mediated in part via SIRT1 activation.

\section{Materials and Methods}

\section{Materials}

EGF was purchased form R\&D System, Inc. (Minneapolis, MN). Resveratorol, SRT1720, PD98059, SB203580, SP600125, deguelin, rapamycin and fasudil were obtained from Calbiochem-Novabiochem Co. (La Jolla, CA). Phospho-specific p44/p42 MAP kinase antibodies, p44/p42 MAP kinase antibodies, phospho-specific p38 MAP kinase antibodies, p38 MAP kinase antibodies, phospho-specific SAPK/JNK antibodies, SAPK/JNK antibodies, phospho-specific Akt antibodies, Akt antibodies, phospho-specific p70 S6 kinase antibodies, phospho-specific MYPT1 antibodies and MYPT1 antibodies were purchased from Cell Signaling Technology, Inc. (Beverly, MA). Glyceraldehyde-3-phosphate dehydrogenase (GAPDH) antibodies were obtained from Santa Cruz Biotechnology, Inc. (Santa Cruz, CA). An ECL Western blotting detection system was obtained from GE Healthcare UK, Ltd. (Buckinghamshire, UK). Other materials and chemicals were obtained from commercial sources. Resveratrol, SRT1720, PD98059, SB203580, SP600125, deguelin, rapamycin or fasudil were dissolved in dimethyl sulfoxide. The maximum concentration of dimethyl sulfoxide was $0.3 \%$, which did not affect the cell migration assay.

\section{KARGER}




\section{Cellular Physiology Cell Physiol Biochem 2017;43:1025-1036 \begin{tabular}{l|l} 
and Biochemistry Published online: October 02, 2017 & $\begin{array}{l}\text { DOI: } 2017 \text { The Author(s). Published by S. Karger AG, Basel } \\
\text { www.karger.com/cpb }\end{array}$
\end{tabular} \\ Kawabata et al.: Resveratrol-Effect on Osteoblast Migration}

\section{Cell culture}

Cloned osteoblast-like MC3T3-E1 cells derived from newborn mouse calvaria [19] were maintained as previously described [20]. Briefly, the cells were cultured in $\alpha$-minimum essential medium ( $\alpha$-MEM) containing $10 \%$ fetal bovine serum (FBS) at $37^{\circ} \mathrm{C}$ in a humidified atmosphere of $5 \% \mathrm{CO}_{2} / 95 \%$ air. The cells were seeded into 90 -mm diameter dishes $\left(2 \times 10^{5}\right.$ cells/dish) in $\alpha$-MEM containing $10 \% \mathrm{FBS}$. After 5 days, the medium was exchanged for $\alpha$-MEM containing $0.3 \%$ FBS. After $48 \mathrm{~h}$, the cells were used for a Western blot analysis. For the cell migration assay, the cultured cells in $\alpha$-MEM containing 10\% FBS for 3 days were sub-cultured in $\alpha$-MEM containing $0.3 \%$ FBS for $6 \mathrm{~h}$ and then used for the experiment.

\section{Cell migration assay}

A cell migration assay was performed as described previously according to Karagiosis [21] using a Boyden chamber (polycarbonate membrane with 8- $\mu$ m pores, Transwell Corning Costar Corp, Cambridge, MA). Briefly, the cultured cells were trypsinized and seeded $\left(1 \times 10^{5}\right.$ cells/well $)$ onto the upper chamber in $\alpha$-MEM containing $0.3 \%$ FBS. Various doses of EGF were added to the lower chamber and incubated at $37^{\circ} \mathrm{C}$ for $16 \mathrm{~h}$. The cells on the upper surface of the membrane were mechanically removed. The migrated cells adherent to the underside of the membrane were fixed $4 \%$ paraformaldehyde and stained with 4,6-diamidino-2-phenylindole (DAPI) solution. The migrated cells were photographed and counted using fluorescent microscopy at a magnification of 20x by counting the stained cells from three randomly chosen high-power fields. When indicated, the cells were pretreated with resveratrol, SRT1720, PD98059, SB203580, SP600125, deguelin, rapamycin or fasudil in the lower chamber for $60 \mathrm{~min}$.

\section{Western blot analysis}

The cultured cells were stimulated by $50 \mathrm{ng} / \mathrm{ml}$ of EGF or vehicle in $1 \mathrm{ml}$ of $\alpha$-MEM containing $0.3 \%$ FBS for the indicated periods. When indicated, the cells were pretreated with resveratrol, SRT1720, PD98059, SB203580, SP600125, deguelin, rapamycin or fasudil in the lower chamber for $60 \mathrm{~min}$. The cells were then lysed, homogenized and sonicated in a lysis buffer containing $62.5 \mathrm{mM}$ Tris $/ \mathrm{HCl}, \mathrm{pH} 6.8,2 \%$ sodium dodecyl sulfate (SDS), $50 \mathrm{mM}$ dithiothreitol and 10\% glycerol. SDS-polyacrylamide gel electrophoresis (PAGE) was performed by the method of Laemmli [22] in 10\% polyacrylamide gels. The protein was fractionated and transferred onto an Immun-Blot PVDF membrane (Bio-Rad, Hercules, CA). The membranes were blocked with 5\% fat-free dry milk in Tris-buffered saline-Tween (TBS-T; $20 \mathrm{mM}$ Tris- $\mathrm{HCl}$, pH 7.6, $137 \mathrm{mM} \mathrm{NaCl}, 0.1 \%$ Tween 20) for $1 \mathrm{~h}$ before incubation with primary antibodies. A Western blot analysis was performed as described previously [23] using phospho-specific p44/p42 MAP kinase antibodies, p44/p42 MAP kinase antibodies, phospho-specific p38 kinase MAP kinase antibodies, p38 MAP kinase antibodies, phosphospecific SAPK/JNK antibodies, SAPK/JNK antibodies, phospho-specific Akt antibodies, Akt antibodies, phospho-specific p70 S6 kinase antibodies, GAPDH antibodies, phospho-specific MYPT1 antibodies or MYPT1 antibodies as primary antibodies with peroxidase-labeled antibodies raised in goat against rabbit IgG (KPL, Inc., Gaithersburg, MD) being used as secondary antibodies. The primary and secondary antibodies were diluted at 1:1000 with 5\% fat-free dry milk in TBS-T. The peroxidase activity on the PVDF sheet was visualized on X-ray film using an ECL Western blotting detection system.

\section{Densitometric analysis}

A densitometric analysis of the Western blots was performed using a scanner and image analysis software program (image J version 1.48; National Institutes of Health, Bethesda, MD). The phosphorylated levels were calculated as follows: the background-subtracted signal intensity of each phosphorylation signal was normalized to the respective intensity of total protein or GAPDH and plotted as the fold increase in comparison to that of the control cells treated without stimulation.

\section{Statistical analysis}

The data were analyzed by an analysis of variance (ANOVA) followed by Bonferroni method for multiple comparisons between pairs, and $p<0.05$ was considered to be statistically significant. All data are presented as the mean \pm standard error of the mean (SEM) of triplicate determinations from three independent cell preparations. 


\section{Results}

Effect of EGF on the migration of MC3T3-E1 cells

EGF reportedly induces the migration of osteoblast-like MC3T3-E1 cells in Matrigel [11]. We found that EGF significantly stimulated the MC3T3-E1 cell migration in a transwell assay using Boyden chamber (Fig. 1). The effect of EGF was dose-dependent over the range of $1-30 \mathrm{ng} / \mathrm{ml}$ (Fig. 1). The maximum effect of EGF on the migration was observed at $10 \mathrm{ng} /$ $\mathrm{ml}$ (Fig. 1). Therefore, we performed subsequent migration experiments with $10 \mathrm{ng} / \mathrm{ml}$ of EGF.

Fig. 1. Effect of EGF on the migration of MC3T3-E1 cells. The cultured cells were stimulated with various concentrations of EGF for $16 \mathrm{~h}$. The migrated cells were fixed with paraformaldehyde and stained with DAPI for nuclei (blue signal). The cells were photographed by fluorescent microscopy at a magnification of $20 x$, and the number of DAPI-stained cells in each field was counted. The upper column shows the fluorescent microscopy image. The lower column shows a histogram showing the number of migrated cells. Each value represents the mean \pm SEM of triplicate determinations from three inde-

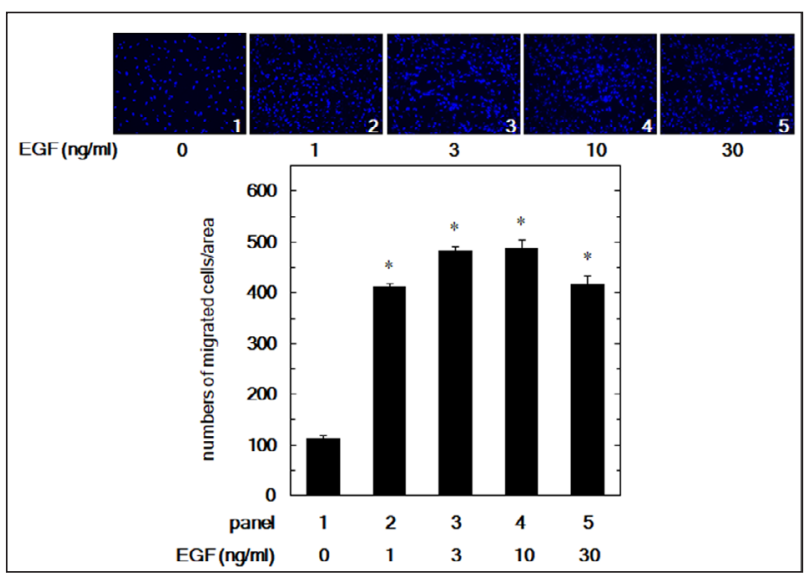
pendent cell preparations. " $\mathrm{p}<0.05$ compared to the value of the control cells without EGF-stimulation.

Fig. 2. Effects of EGF on the phosphorylation of p44/p42 MAP kinase, p38 MAP kinase, SAPK/ JNK, Akt, p70 S6 kinase or MYPT in MC3T3E1 cells. The cultured cells were stimulated by $30 \mathrm{ng} / \mathrm{ml}$ of EGF for the indicated periods. The extracts of the cells were then subjected to SDS-PAGE with a subsequent Western blot analysis using antibodies against phosphospecific p44/p42 MAP kinase, phospho-specific p38 MAP kinase, phospho-specific SAPK/ JNK, phospho-specific Akt, phospho-specific phospho-specific p70 S6 kinase, phosphospecific MYPT1 and GAPDH. The histogram shows the quantitative representations of the EGF-induced levels of phosphorylation of $\mathrm{p} 44$ / p42 MAP kinase, p38 MAP kinase, SAPK/JNK, Akt, p70 S6 kinase or MYPT1 obtained from laser densitometric analysis.

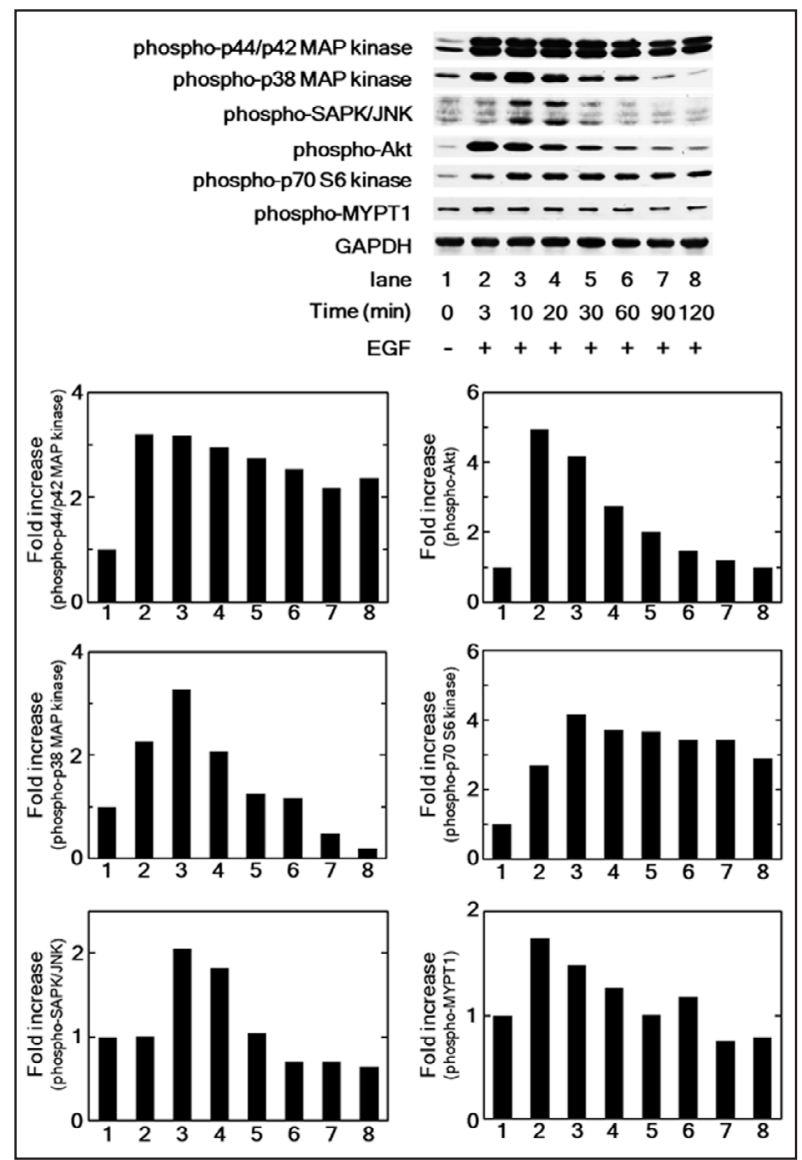


Fig. 3. Effects of PD98059, SB203580, SP600125, deguelin, rapamycin or fasudil on the EGFinduced migration of MC3T3-E1 cells. The cells were pretreated with $50 \mu \mathrm{M}$ of PD98059 (A), 20 $\mu \mathrm{M}$ of SB203580 (B), $7 \mu \mathrm{M}$ of SP600125 (C), $0.5 \mu \mathrm{M}$ of deguelin (D), $50 \mathrm{ng} / \mathrm{ml}$ of rapamycin (E), $30 \mu \mathrm{M}$ of fasudil (F) or vehicle for $60 \mathrm{~min}$ and then stimulated by $10 \mathrm{ng} / \mathrm{ml}$ of EGF or vehicle for $16 \mathrm{~h}$. The migrated cells were fixed with paraformaldehyde and stained with DAPI for nuclei (blue signal). The cells were photographed by fluorescent microscopy at a magnification of $20 \mathrm{x}$, and the number of DAPI-stained cells in each field were counted. The upper column shows the fluorescent microscopy image. The lower column shows a histogram showing the number of migrated cells. Each value represents the mean \pm SEM of triplicate determinations from three independent cell preparations. ${ }^{*} \mathrm{p}<0.05$ compared to the value of the control cells without EGF stimulation. ${ }^{*} \mathrm{p}<0.05$ compared to the value of EGF alone. N.S., no significant difference between the indicated pairs.

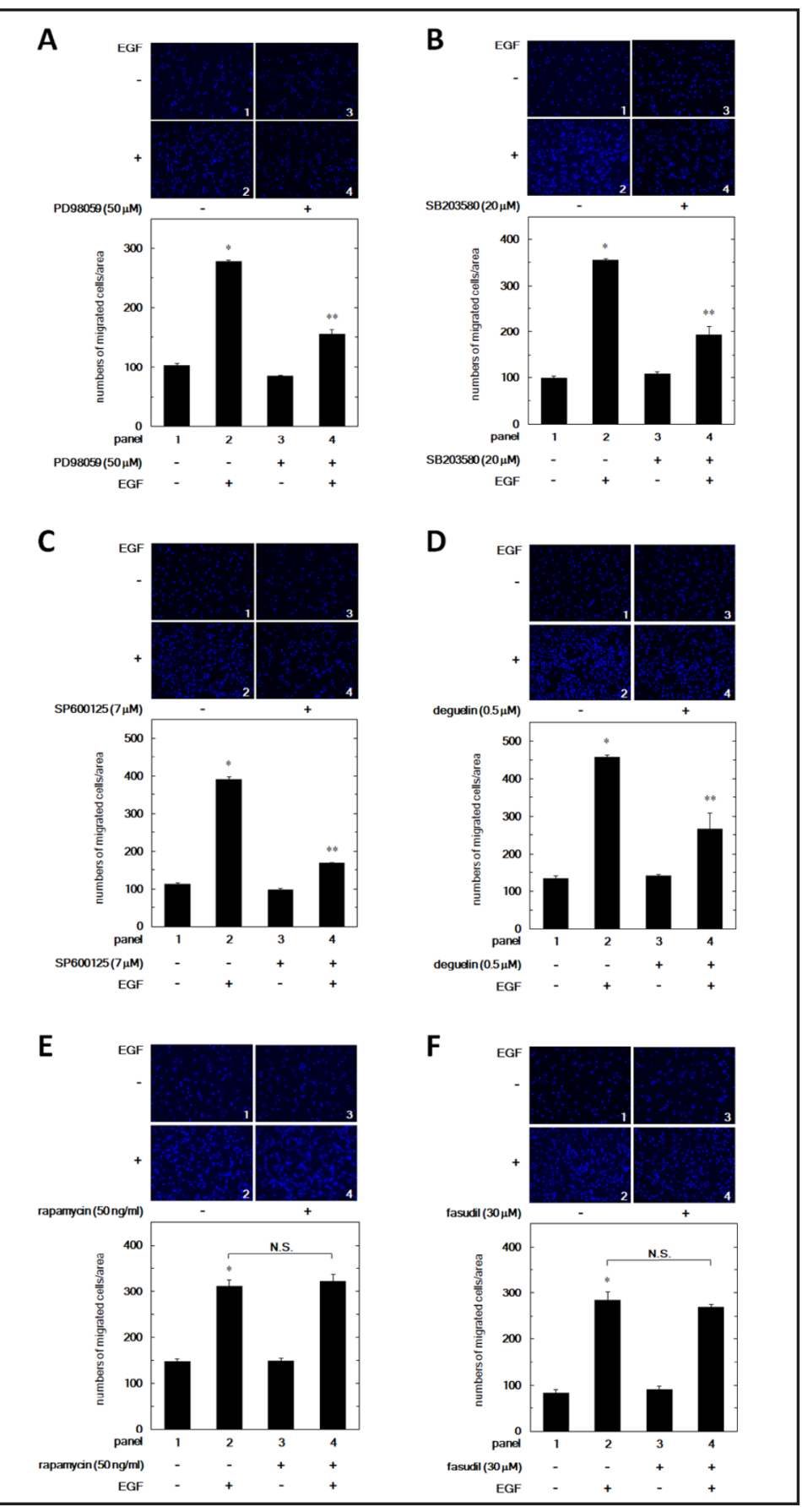

Effects of EGF on the phosphorylation of 44 /p42 MAP kinase, p38 MAP kinase, SAPK/JNK, Akt, $p 70$ S6 kinase and MYPT1 in MC3T3-E1 cells

Regarding the intracellular signaling system in the EGF-induced migration, the pathways of PI3K/Akt and p38 MAP kinase have been shown to play a role in the EGF-stimulated migration of intestinal epithelial cells and mesenchymal progenitor cells [24-26]. It is firmly established that p44/p42 MAP kinase and SAPK/JNK in addition to p38 MAP kinase among the MAP kinase superfamily are central elements used by mammalian cells to transduce the various messages of a variety of stimulators [27]. In our previous study [28], we demonstrated that Rho-kinase acts as a negative regulator in the EGF-induced migration of colon cancer cells. Additionally, p70 S6 kinase is reportedly implicated in ovarian cancer cell 


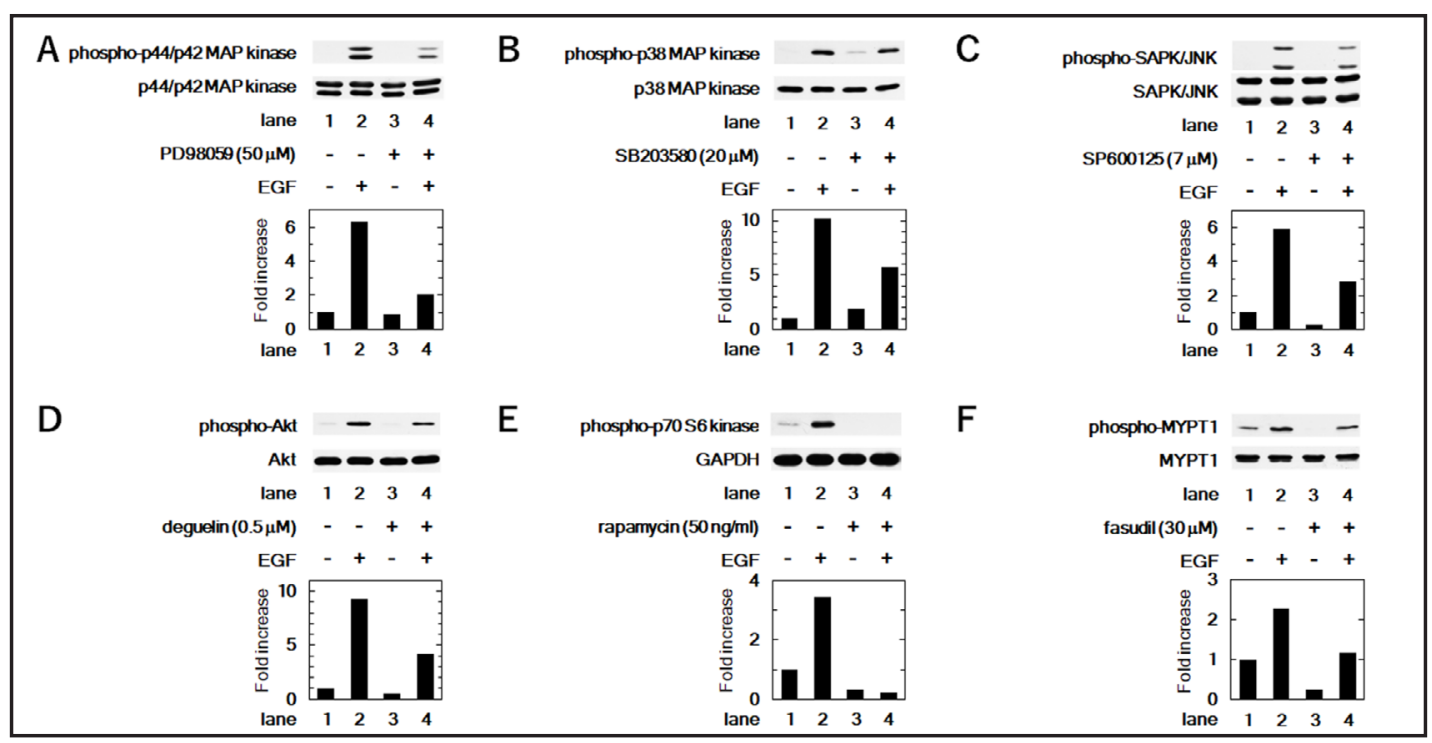

Fig. 4. Effects of PD98059, SB203580, SP600125, deguelin, rapamycin and fasudil on the EGF-induced phosphorylation of p44/p42 MAP kinase, p38 MAP kinase, SAPK/JNK, Akt, p70 S6 kinase and MYPT1, respectively, in MC3T3-E1 cells. The cells were pretreated with $50 \mu \mathrm{M}$ of PD98059 (A), $20 \mu \mathrm{M}$ of SB203580 (B), $7 \mu \mathrm{M}$ of SP600125 (C), $0.5 \mu \mathrm{M}$ of deguelin (D), $50 \mathrm{ng} / \mathrm{ml}$ of rapamycin (E), $30 \mu \mathrm{M}$ of fasudil (F) or vehicle for $60 \mathrm{~min}$. The cultured cells were then stimulated by $50 \mathrm{ng} / \mathrm{ml}$ of EGF or vehicle for $3 \mathrm{~min}(\mathrm{~A}, \mathrm{D}, \mathrm{E})$ or 10 $\min (\mathrm{B}, \mathrm{C}, \mathrm{F})$. The extracts of cells were subjected to SDS-PAGE with a subsequent Western blot analysis using antibodies against phospho-specific p44/p42 MAP kinase, p44/p42 MAP kinase, phospho-specific p38 MAP kinase, p38 MAP kinase, phospho-specific SAPK/JNK, SAPK/JNK, phospho-specific Akt, Akt, phosphospecific p70 S6 kinase, GAPDH, phospho-specific MYPT1 or MYPT1. The histogram shows the quantitative representations of the EGF-induced levels of phosphorylation of p44/p42 MAP kinase, p38 MAP kinase, SAPK/JNK, Akt, p70 S6 kinase or MYPT1 obtained from laser densitometric analysis.

migration [29]. We found that EGF markedly induced the phosphorylation of $\mathrm{p} 44 / \mathrm{p} 42 \mathrm{MAP}$ kinase, p38 MAP kinase, SAPK/JNK, Akt, p70 S6 kinase and MYPT1, a down-stream substrate of Rho-kinase [30], in osteoblast-like MC3T3-E1 cells (Fig. 2). These findings suggest that EGF stimulates the activation of p44/p42 MAP kinase, p38 MAP kinase, SAPK/JNK, Akt, p70 S6 kinase and Rho-kinase in these cells.

Effects of PD98059, SB203580, SP600125, deguelin, rapamycin or fasudil on the EGFinduced migration of MC3T3-E1 cells

To investigate how EGF induces the migration of osteoblast-like MC3T3-E1 cells, we examined the effects of PD98059, an inhibitor of the upstream kinase activating p44/p42 MAP kinase (MEK1/2) [31]; SB203580, an inhibitor of p38 MAP kinase [32]; SP600125, an inhibitor of SAPK/JNK [33]; deguelin, an inhibitor of Akt [34]; rapamycin, an inhibitor of mammalian target of rapamycin (mTOR) that activates p70 S6 kinase [35]; and fasudil, an inhibitor of Rho-kinase [30], on the EGF-induced MC3T3-E1 cell migration. PD98059, SB203580, SP600125 and deguelin, which alone had little effect on the migration, significantly reduced the EGF-induced cell migration (Figs. 3A, 3B, 3C and 3D), whereas rapamycin and fasudil failed to affect the cell migration (Figs. $3 \mathrm{E}$ and $3 \mathrm{~F}$ ). In addition, we found that PD98059, SB203580, SP600125, deguelin, rapamycin and fasudil each acted as an inhibitor of their respective targets in these cells (Figs. 4A, 4B, 4C, 4D, 4E and 4F).

Effect of resveratrol on the EGF-induced migration of MC3T3-E1 cells

Resveratrol is generally known as a natural polyphenol abundantly found in grape skins and red wine [14], and it has recently been shown that women, who preferentially 


\section{Cellular Physiology Cell Physiol Biochem 2017;43:1025-1036 \begin{tabular}{ll|l} 
DOI: 10.1159/000481700 & O 2017 The Author(s). Published by S. Karger AG, Basel \\
www.karger.com/cpb
\end{tabular}

Fig. 5. Effect of resveratrol on the EGF-induced migration of MC3T3-E1 cells. The cells were pretreated with various doses of resveratrol for $60 \mathrm{~min}$, and then stimulated by $50 \mathrm{ng} / \mathrm{ml}$ of EGF or vehicle for $16 \mathrm{~h}$. The migrated cells were fixed with paraformaldehyde, and stained with DAPI for nuclei (blue signal). The cells were photographed by fluorescent microscopy at a magnification of $20 x$, and the number of DAPI-stained cells in each field was counted. The upper column shows the fluorescent microscopy image. The lower column shows a histogram showing the number of migrated cells. Each value represents the mean \pm SEM of triplicate determinations from three independent cell preparations. ${ }^{*} \mathrm{p}<0.05$ compared to the value of the control cells without EGF stimulation. ${ }^{* *} \mathrm{p}<0.05$ compared to the value of EGF alone.

Fig. 6. Effect of SRT1720 on the EGF-induced migration of MC3T3-E1 cells. The cells were pretreated with various doses of SRT1720 for 60 min and then stimulated by $50 \mathrm{ng} / \mathrm{ml}$ of EGF or vehicle for $16 \mathrm{~h}$. The migrated cells were fixed with paraformaldehyde and stained with DAPI for nuclei (blue signal). The cells were photographed by fluorescent microscopy at a magnification of 20x, and the number of DAPI-stained cells in each field was counted. The upper column shows the fluorescent microscopy image. The lower column shows a histogram showing the number of migrated cells. Each value represents the mean \pm SEM of triplicate determinations from three independent cell preparations. ${ }^{*} \mathrm{p}<0.05$ compared to the value of the control cells without EGF stimulation. ${ }^{* *} \mathrm{p}<0.05$ compared to the value of EGF alone.
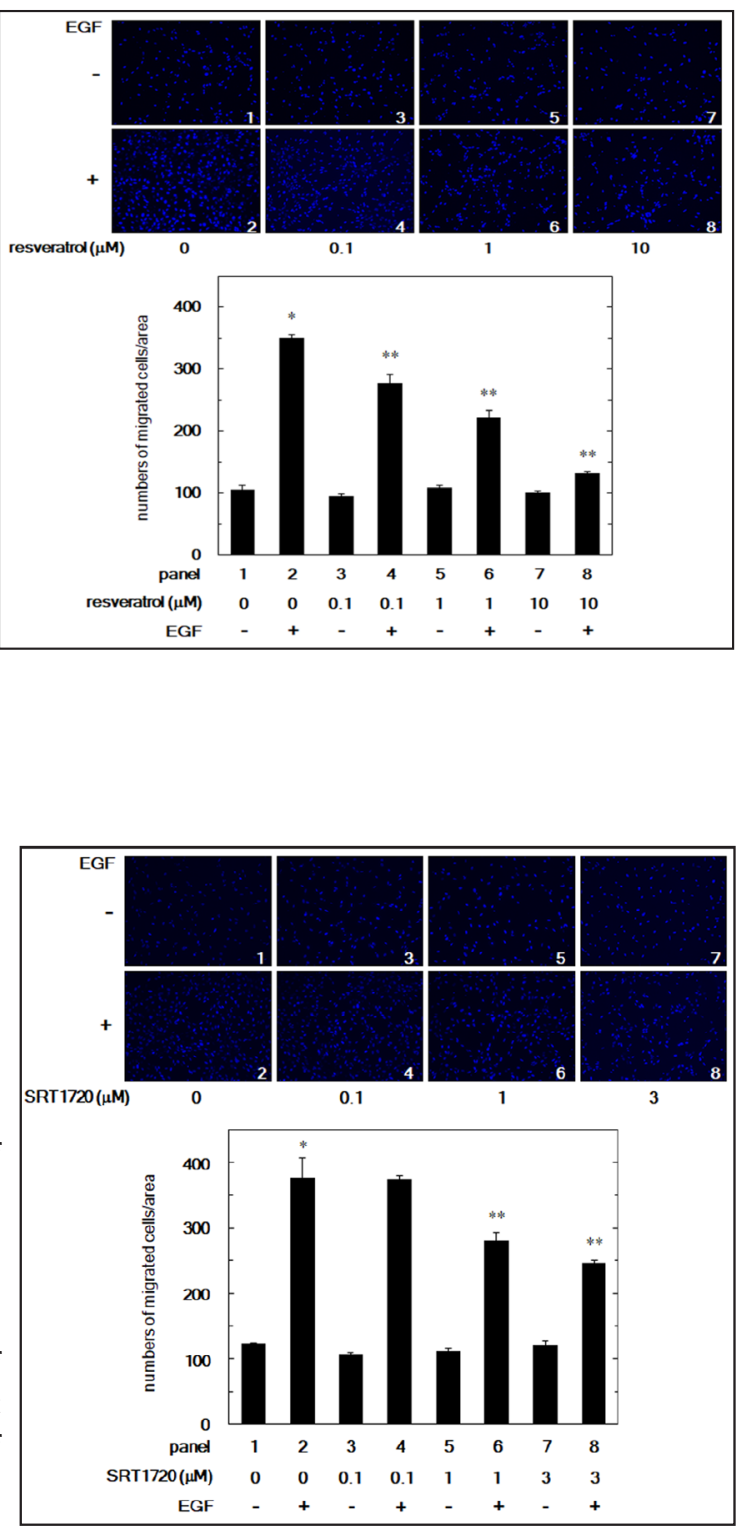

consume wine, have a lower risk of hip fracture [17]. Therefore, we examined whether or not resveratrol affects the EGF-induced migration of osteoblast-like MC3T3-E1 cells. Resveratrol, which alone had little effect on the cell migration, significantly reduced the EGF-induced migration of MC3T3-E1 cells (Fig. 5). The suppressive effect of resveratrol was dose-dependent over the range of 0.1-10 $\mu \mathrm{M}$.

\section{Effect of SRT1720 on the EGF-induced migration of MC3T3-E1 cells}

It has been reported that the several effects of resveratrol are dependent on SIRT1 activation $[18,36]$. Therefore, we examined whether or not SRT1720, an SIRT1 activator [37], affects the EGF-induced migration of osteoblast-like MC3T3-E1 cells. SRT1720, which alone hardly affected the cell migration, significantly reduced the EGF-induced cell migration in a dose-dependent manner over the range of 0.1-3 $\mu \mathrm{M}$ (Fig. 6). 


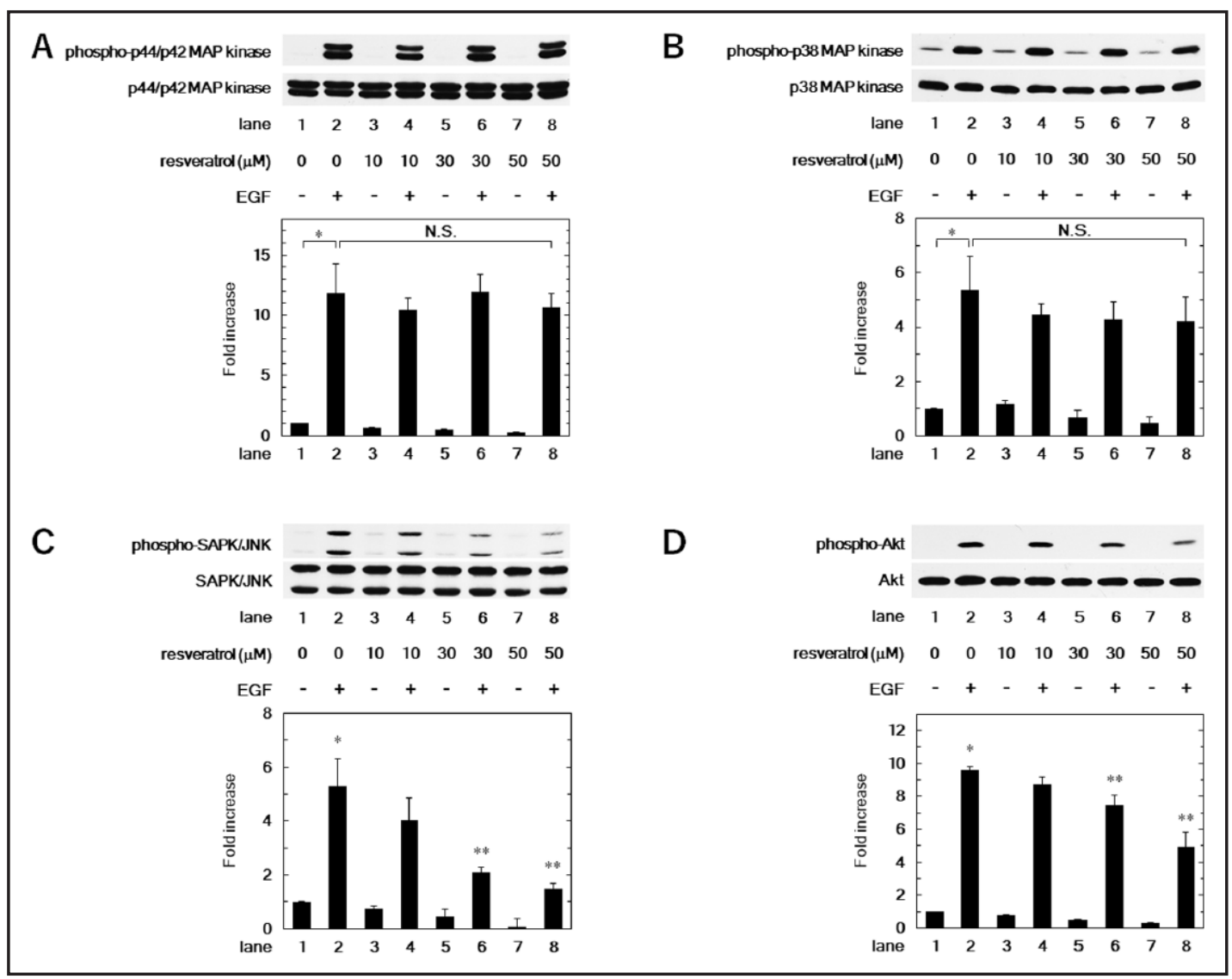

Fig. 7. Effects of resveratrol on the EGF-induced phosphorylation of p44/p42 MAP kinase (A), p38 MAP kinase (B), SAPK/JNK (C) or Akt (D) in MC3T3-E1 cells. The cells were pretreated with various doses of resveratrol for $60 \mathrm{~min}$ and then stimulated by $50 \mathrm{ng} / \mathrm{ml}$ of EGF or vehicle for $3 \mathrm{~min}$ (A,D) or $10 \mathrm{~min}(\mathrm{~B}, \mathrm{C})$. The extracts of cells were subjected to SDS-PAGE with a subsequent Western blot analysis using antibodies against phospho-specific p44/p42 MAP kinase, p44/p42 MAP kinase, phospho-specific p38 MAP kinase, p38 MAP kinase, phospho-specific SAPK/JNK, SAPK/JNK, phospho-specific Akt or Akt. The histogram shows the quantitative representations of the EGF-induced levels from a laser densitometric analysis of these independent experiments. Each value represents the mean \pm SEM of triplicate determinations from three independent cell preparations. * $\mathrm{p}<0.05$ compared to the value of the control cells without EGF stimulation. * $\mathrm{p}<0.05$ compared to the value of EGF alone. N.S., no significant differences between the indicated pairs.

Effects of resveratrol on the EGF-induced phosphorylation of p44/p42 MAP kinase, p38 MAP kinase, SAPK/JNK or Akt in MC3T3-E1 cells

In order to clarify the mechanism behind the inhibition by resveratrol of the EGF-induced MC3T3-E1 cell migration, we next examined the effect of resveratrol on the EGF-stimulated phosphorylation of p44/p42 MAP kinase, p38 MAP kinase, SAPK/JNK and Akt. However, resveratrol did not affect the EGF-induced phosphorylation of $\mathrm{p} 44 / \mathrm{p} 42$ MAP kinase or $\mathrm{p} 38$ MAP kinase (Figs. 7A and 7B). In contrast, resveratrol significantly reduced the EGF-induced phosphorylation of SAPK/JNK and Akt (Figs. 7C and 7D).

Effects of SRT1720 on the EGF-induced phosphorylation of SAPK/JNK or Akt in MC3T3-E1 cells

In order to investigate whether or not the suppressive effect of resveratrol on the EGFstimulated MC3T3-E1 cell migration is mediated through SIRT1, we further examined the effects of SRT1720 on the EGF-induced phosphorylation of SAPK/JNK and Akt. SRT1720 KARGER 
Fig. 8. Effects of SRT1720 on the EGF-induced phosphorylation of SAPK/JNK or Akt in MC3T3-E1 cells. The cells were pretreated with various doses of SRT1720 for 60 min, and then stimulated by $50 \mathrm{ng} / \mathrm{ml}$ of EGF or vehicle for $10 \mathrm{~min}(\mathrm{~A})$ or $3 \mathrm{~min}(\mathrm{~B})$. The extracts of cells were subjected to SDS-PAGE with a subsequent Western blot analysis using antibodies against phospho-specific SAPK/JNK, SAPK/ JNK, phospho-specific Akt or Akt. The histogram shows the quantitative representations of the EGF-induced levels from a laser densitometric analysis of these independent experiments. Each value represents the mean \pm SEM of triplicate determinations from three independent cell preparations. ${ }^{*} \mathrm{p}<0.05$ compared to the value of the control cells without EGF stimulation. ${ }^{*} \mathrm{p}<0.05$ compared to the value of EGF alone.

markedly reduced the EGF-induced phosphorylation of SAPK/JNK and Akt in a dose-dependent manner over the range of 10-30 $\mu \mathrm{M}$ (Figs. 8A and 8B).

\section{Discussion}

In the present study, we demonstrated that resveratrol, a natural polyphenolic flavonoid enriched in red grape and berries, significantly suppressed the EGF-induced migration in osteoblastlike MC3T3-E1 cells. Several effects of resveratrol are known to be exerted through SIRT1 activation $[18,36]$. Therefore, we examined whether or not the

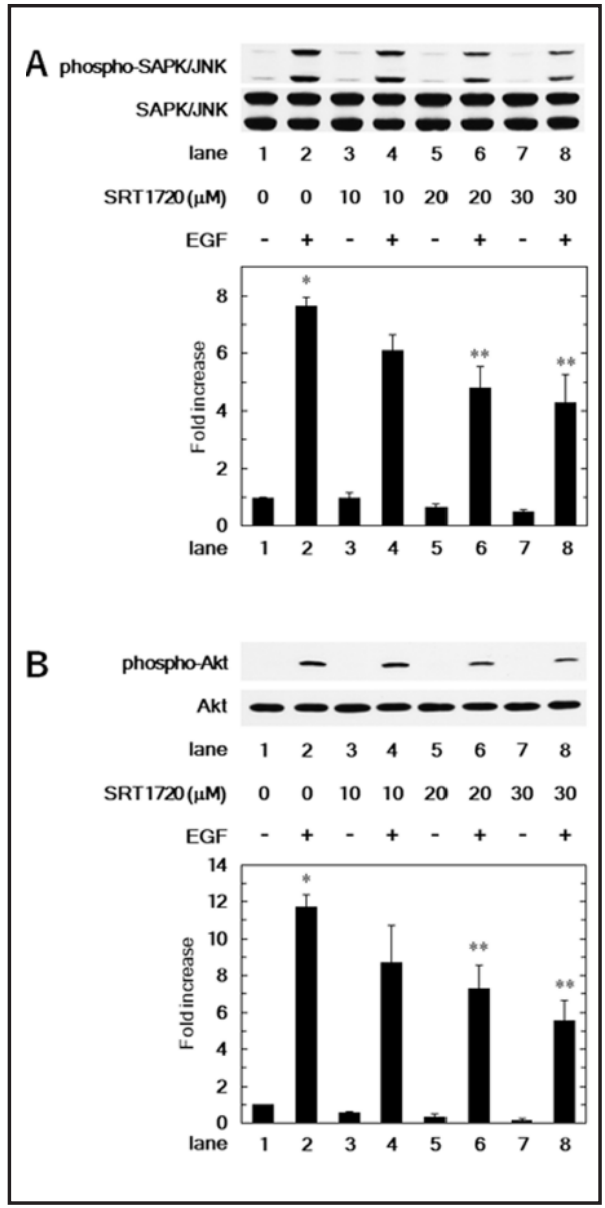
EGF-stimulated MC3T3-E1 cell migration is affected by SRT1720, a potent activator of SIRT1 [37], and found that SRT1720 as well as resveratrol markedly reduced the EFG-induced cell migration. Based on our findings, it is most likely that the inhibition by resveratrol of EGF-induced osteoblast-like MC3T3-E1 cell migration is exerted at least in part through SIRT1 activation.

We next investigated the mechanism behind EGF-stimulated migration of osteoblast-like MC3T3-E1 cells and the suppression by resveratrol. Regarding the intracellular signaling in the migration of osteoblasts, it has been shown that parathyroid hormone increases the release of amphiregulin, an EGF receptor ligand, from osteoblastic cells, which binds to the EGF receptor expressed on mesenchymal progenitors to stimulate the p38 MAP kinase and Akt pathways, and subsequently promotes their migration [24]. Among the MAP kinase superfamily, three MAP kinases-p44/p42 MAP kinase, p38 MAP kinase and SAPK/JNK—are recognized to function as central intracellular elements to transduce the diverse messages [27]. In contrast, Rho-kinase reportedly acts as a negative regulator in migration of osteoblasts [38]. In addition, accumulating evidence suggests that p70 S6 kinase is implicated in the migration of several cancer cells [29]. We found that EGF induced the phosphorylation of p44/p42 MAP kinase, p38 MAP kinase, SAPK/JNK, Akt, p70 S6 kinase and MYPT1, a target of Rho-kinase in osteoblast-like MC3T3-E1 cells, certified by densitometry. Therefore, in order to clarify which kinase plays a critical role in the EGF-induced MC3T3-E1 cell migration, we examined the effects of each inhibitor of p44/p42 MAP kinase, p38 MAP kinase, JNK, Akt, p70 S6 kinase and Rho-kinase on the cell migration. We showed that PD98059 [31], SB203580 [32], SP600125 [33] and deguelin [34] reduced the EGF-induced phosphorylation of p44/ p42 MAP kinase, p38 MAP kinase, SAPK/JNK and Akt, respectively, certified by densitometry. In contrast, we found that rapamycin [35] and fasudil [30] did not affect the phosphorylation 
of p70 S6 kinase and MYPT1, respectively. We confirmed that each inhibitor truly functioned in MC3T3-E1 cells under EGF-stimulated conditions. Therefore, our findings suggest that p44/p42 MAP kinase, p38 MAP kinase, SAPK/JNK and Akt function as positive regulators in the EGF-induced migration of osteoblast-like MC3T3-E1 cells.

We further investigated the exact mechanism underlying the suppression by resveratrol of EGF-induced osteoblast-like MC3T3-E1 cell migration. Interestingly, resveratrol markedly attenuated the EGF-stimulated phosphorylation of both SAPK/JNK and Akt without affecting the phosphorylation of p44/p42 MAP kinase or p38 MAP kinase, certified by densitometry. Our findings therefore suggest that resveratrol inhibits the EGF-induced migration by suppressing SAPK/JNK and Akt in osteoblast-like MC3T3-E1 cells. Furthermore, we showed that the EGF-stimulated phosphorylation of SAPK/JNK and Akt was significantly suppressed by SRT1720 [37] in addition to resveratrol. Taking together, our findings suggest that resveratrol reduces the EGF-induced migration of osteoblast-like MC3T3-E1 cells through the inhibition of SAPK and Akt, and that the suppressive effect of resveratrol is mediated through SIRT1 activation. To our knowledge, this is the first report showing that resveratrol negatively regulates the migration of osteoblasts. It is generally recognized that the migration of osteoblasts to the bone remodeling sites is crucial for not only physiological bone metabolism but also pathological states such as bone fracture repair and osteoporosis [3-5]. To adequate migration of osteoblasts is considered to be essential for maintaining both the quality and the quantity of bone mass, which requires organized bone turnover. Given the favorable effects of resveratrol on human health, particularly bone health [17], it is possible that the suppressive effect of resveratrol on the EGF-induced osteoblast migration induces adequate cell migration for bone remodeling. It has been shown that microRNA-10a plays a suppressive role in the osteogenic differentiation of MC3T3-E1 cells by regulating the $\beta$-catenin expression [39]. Thus, it is possible that the modification of Wnt/ $\beta$-catenin signaling pathway is involved in the mechanism underlying the suppression by resveratrol of EGF-induced migration of osteoblast-like MC3T3-E1 cells shown here. In addition, it has recently been reported that electro-acupuncture promotes the mobilization of endogenous multipotential mesenchymal stem cell, the precursor of osteoblast-lineage, into the peripheral blood [40]. So, it is likely that several approaches such as natural nutrients including resveratrol and physical stimulations like electro-acupuncture provide beneficial effects on the accomplishment of adequate bone metabolism. Further investigations are necessary to elucidate the exact mechanism by which resveratrol affects the EGF-induced migration of osteoblasts.

In conclusion, our results strongly suggest that resveratrol inhibits the EGF-induced migration of osteoblasts via the suppression of SAPK and Akt, and that the inhibitory effect of resveratrol is mediated in part via SIRT1 activation.

\section{Acknowledgements}

We are very grateful to Yumiko Kurokawa for her skillful technical assistance. This investigation was supported in part by a Grant-in-Aid for Scientific Research (26462289, 15K10487) from the Ministry of Education, a Grant-in-Aid for Scientific Research (H25Aging-General-004) from the Ministry of Health, Labour and Welfare, and the Research Funding for Longevity Sciences (25-4, 26-12) from National Center for Geriatrics and Gerontology (NCGG), Japan.

\section{Disclosure Statement}

All authors declare no Disclosure Statement. 


\section{Cellular Physiology Cell Physiol Biochem 2017;43:1025-1036

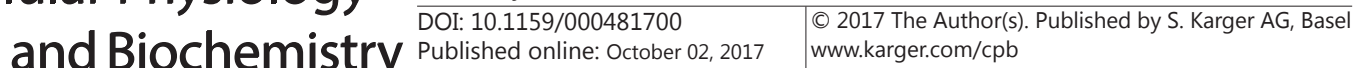

Kawabata et al.: Resveratrol-Effect on Osteoblast Migration

\section{References}

1 Karsenty G, Wagner EF: Reaching a genetic and molecular understanding of skeletal development. Dev Cell 2002;2:389-406.

-2 Kular J, Tickner J, Chim SM, Xu J: An overview of the regulation of bone remodeling at the cellular level. Clin Biochem 2012;45:863-873.

-3 Khan SN, Bostrom MP, Lane JM: Bone growth factors. Orthop Clin North Am 2000;31:375-388.

4 Lieberman JR, Daluiski A, Einhorn TA: The role of growth factors in the repair of bone. Biology and clinical applications. J Bone Joint Surg Am 2002;84-A:1032-1044.

$\checkmark 5$ Reddi AH, Roodman D, Freeman C, Mohla S: Mechanisms of tumor metastasis to the bone: Challenges and opportunities. J Bone Miner Res 2003;18:190-194.

6 Schneider MR, Sibilia M, Erben RC: The EGFR network in bone biology and pathology. Trends Endocrinol Metab 2009;20:517-524.

7 Ng KW, Partridge NC, Niall M, Martin TJ: Stimulation of DNA synthesis by epidermal growth factor in osteoblast-like cells. Calcif Tissue Int 1983;35:624-628.

8 Fang MA, Kujubu DA, Hahn TJ: The effects of prostaglandin E2, parathyroid hormone, and epidermal growth factor on mitogenesis, signaling, and primary response genes in UMR 106-01 osteoblast-like cells. Endocrinology 1992;131:2113-2119.

-9 Kumegawa M, Hiramatsu M, Hatakeyama K, Yajima T, Kodama H, Osaki T, Kurisu K: Effects of epidermal growth factor on osteoblastic cells in vitro. Calcif Tissue Int 1983;35:542-548.

10 Hata R, Hori H, Nagai Y, Tanaka S, Kondo M, Hiramatsu M, Utsumi N, Kumegawa M: Selective inhibition of type I collagen synthesis in osteoblastic cells by epidermal growth factor. Endocrinology 1984;115:867876.

11 Vukicevic S, Kleinman HK, Luyten FP, Roberts AB, Roche NS, Reddi AH: Identification of multiple active growth factors in basement membrane Matrigel suggests caution in interpretation of cellular activity related to extracellular matrix components. Exp Cell Res 1992;202:1-8.

-12 Jankun J, Selman SH, Wiercz RS, Skrzypczak-Jankun E: Why drinking green tea could prevent cancer. Nature 1997;387:561.

13 Harbourne JB, Williams CA: Advances in flavonoid research since 1992. Phytochemistry 2000;55:481-504.

14 Blander G, Guarente L: The Sir2 family of protein deacetylases. Annu Rev Biochem 2004;73:417-435.

15 Koo SH, Montminy M: In vino veritas: A tale of two Sirt1s. Cell 2006;127:1091-1093.

16 Renaud S, de Lorgeril M: Wine, alcohol, platelets, and the French paradox for coronary heart disease. Lancet 1992;339:1523-1526.

17 Kubo JT, Stefanick ML, Robbins J, Wactawski-Wende J, Cullen MR, Freiberg M, Desai M: Preference for wine is associated with lower hip fracture incidence in post-menopausal women. BMC Womens Health 2013;13:36.

18 Baur JA, Pearson KJ, Price NL, Jamieson HA, Lerin C, Kalra A, Allard VV, Prabhu JS, Lopez-Lluch G, Lewis K: Resveratrol improves health and survival of mice on a high-calorie diet. Nature 2006;444:337-342.

19 Sudo H, Kodama H, Amagai Y, Yamamoto S, Kasai S: In vitro differentiation and calcification in a new clonal osteogenic cell line derived from newborn mouse calvaria. J Cell Biol 1983;96:191-198.

-20 Kozawa 0, Tokuda H, Miwa M, Kotoyori J, Oiso Y: Cross-talk regulation between cyclic AMP production and phosphoinositide hydrolysis induced by prostaglandin E2 in osteoblast-like cells. Exp Cell Res 1992;198:130-134.

21 Karagiosis SA, Chrisler WB, Bollinger N, Karin NJ: Lysophosphatidic acid-induced ERK activation and chemotaxis in MC3T3-E1 preosteoblasts are independent of EGF receptor transactivation. J Cell Physiol 2009;219:716-723.

22 Laemmli UK: Cleavage of structural proteins during the assembly of the head of bacteriophage T4. Nature 1970;227:680-685.

23 Kato K, Ito H, Hasegawa K, Inaguma Y, Kozawa O, Asano T: Modulation of the stress-induced synthesis of hsp27 and $\alpha B$-crystallin by cyclic AMP in C6 rat glioma cells. J Neurochem 1996;66:946-950.

24 Zhu J, Siclari VA, Liu F, Spatz JM, Chandra A, Divieti Pajevic P, Qin L: Amphiregulin-EGFR signaling mediates the migration of bone marrow mesenchymal progenitors toward PTH-stimulated osteoblasts and osteocytes. PLoS One 2012;7:e50099. 


\section{Cellular Physiology Cell Physiol Biochem 2017;43:1025-1036

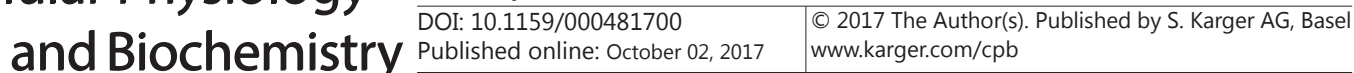 \\ Kawabata et al.: Resveratrol-Effect on Osteoblast Migration}

-25 Frey MR, Golovin A, Polk DB: Epidermal growth factor-stimulated intestinal epithelial cell migration requires Src family kinase-dependent p38 MAPK signaling. J Biol Chem 2004;279:44513-44521.

-26 Polk DB: Epidermal growth factor receptor-stimulated intestinal epithelial cell migration requires phospholipase C activity. Gastroenterology 1998;114:493- 502.

27 Widmann C, Gibson S, Jarpe MB, Johnson GL: Mitogen-activated protein kinase: Conservation of a threekinase module from yeast to human. Physiol Rev 1999;79:143-180.

-28 Adachi S, Yasuda I, Nakashima M, Yamauchi T, Yoshioka T, Okano Y, Moriwaki H, Kozawa O: Rho-kinase inhibitor upregulates migration by altering focal adhesion formation via the Akt pathway in colon cancer cells. Eur J Pharmacol 2011;650:145-150.

29 lp CK, Cheung AN, Ngan HY, Wong AS: p70 S6 kinase in the control of actin cytoskeleton dynamics and directed migration of ovarian cancer cells. Oncogene 2011;30:2420-2432.

30 Shimokawa H, Rashid M: Development of Rho-kinase inhibitors for cardiovascular medicine. Trends Pharmacol Sci 2007;28:296-302.

-31 lessi DR, Cuenda A, Cohen P, Dudley DT, Saltiel AR: PD 098059 is a specific inhibitor of the activation of mitogen-activated protein kinase kinase in vitro and in vivo. J Biol Chem 1995;270:27489-27494.

-32 Cuenda A, Rouse J, Doza YN, Meier R, Cohen P, Gallagher TF, Young PR, Lee JC: SB 203580 is a specific inhibitor of a MAP kinase homologue which is stimulated by cellular stresses and interleukin-1. FEBS Lett 1995;364:229-233.

33 Bennett BL, Sasaki DT, Murray BW, O’Leary EC, Sakata ST, Xu W, Leisten JC, Motiwala A, Pierce S, Satoh Y: SP600125, an anthrapyrazolone inhibitor of Jun N-terminal kinase. Proc Natl Acad Sci U.S.A. 2001;98:13681-13686.

-34 Toker A, Newton AC: Cellular signaling: Pivoting around PDK-1. Cell 2000;103:185-188.

-35 Li Y, Corradetti MN, Inoki K, Guan KL: TSC2: filling the GAP in the mTOR signaling pathway. Trend Biochem Sci 2004;29:32-38.

-36 Baur JA, Pearson KJ, Price NL, Jamieson HA, Lerin C, Kalra A, Prabhu VV , Allard JS, Lopez-Lluch G, Lewis K, Pistell PJ, Poosala S, Becker KG, Boss O, Gwinn D, Wang M, Ramaswamy S, Fishbein KW, Spencer RG, Lakatta EG, Le Couteur D, Shaw RJ, Navas P, Puigserver P, Ingram DK, de Cabo R, Sinclair DA: Resveratrol improves health and survival of mice on a high-calorie diet Nature 2006;444:37-42.

-37 Milne JC, Lambert PD, Schenk S, Carney DP, Smith JJ, Gagne DJ, Jin L, Boss O, Perni RB, Vu CB, Bemis JE, Xie R, Disch JS, Ng PY, Nunes JJ, Lynch AV, Yang H, Galonek H, Israelian K, Choy W, Iffland A, Lavu S, Medvedik O, Sinclair DA, Olefsky JM, Jirousek MR, Elliott PJ, Westphal CH: Small molecule activators of SIRT1 as therapeutics for the treatment of type 2 diabetes. Nature 2007;450:712-716.

-38 Zhang X, Li C, Gao H, Nabeka H, Shimokawa T, Wakisaka H, Matsuda S, Kobayashi N: Rho kinase inhibitors stimulate the migration of human cultured osteoblastic cells by regulating actomyosin activity. Cell Mol Biol Lett 2011;16:279-295.

-39 Li J, Zhang Y, Zhao Q Wang J, He X: MicroRNA-10a influences osteoblast differentiation and angiogenesis by regulating $\beta$-catenin expression. Cell Physiol Biochem 2015;37:2194-2208.

40 Liu L, Yu Q, Hu K, Wang B, Zhang Y, Xu Y, Fu S, Yu X, Huang H: Electro-acupuncture promotes endogenous multipotential mesenchymal stem cell mobilization into the peripheral blood. Cell Physiol Biochem 2016;38:1605-1617. 